\title{
Intermittent patterns of synchronous activity in human basal
} ganglia

\author{
Choongseok Park ${ }^{1}$, Robert M Worth ${ }^{2,1}$ and Leonid L Rubchinsky*1,3
}

Address: ${ }^{1}$ Department of Mathematical Sciences and Center for Mathematical Biosciences, Indiana University Purdue University Indianapolis, Indianapolis, IN 46202, USA, ${ }^{2}$ Department of Neurosurgery, Indiana University School of Medicine, Indianapolis, IN 46202, USA and ${ }^{3}$ Stark Neurosciences Research Institute, Indiana University School of Medicine, Indianapolis, IN 46202, USA

Email: Leonid L Rubchinsky* - leo@math.iupui.edu

* Corresponding author

from Seventeenth Annual Computational Neuroscience Meeting: CNS*2008

Portland, OR, USA. 19-24 July 2008

Published: II July 2008

BMC Neuroscience 2008, 9(SuppI I):PI50 doi:I0.II86/I47I-2202-9-SI-PI50

This abstract is available from: http://www.biomedcentral.com/I47I-2202/9/SI/PI 50

(c) 2008 Park et al; licensee BioMed Central Ltd.

\section{Introduction}

Basal ganglia (BG) are involved in control of movement and are impacted in Parkinson's disease (PD). This impact is believed to be responsible for the symptoms. Recent studies provided evidence for the significance of oscillatory activity in beta and gamma bands for BG physiology in both health and disease, such as PD and dystonia [1,2]. The dynamics of the oscillations and their mechanisms are the subjects of this study.

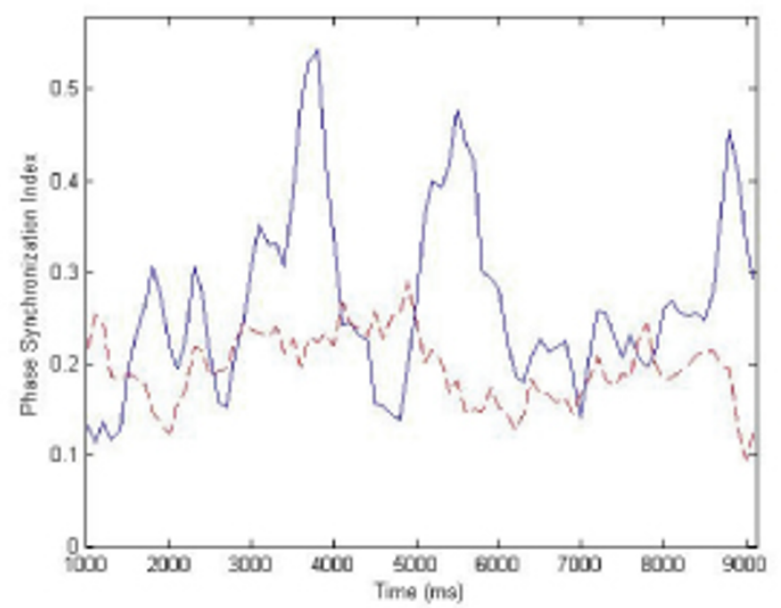

\section{Methods}

We record intraoperatively from subthalamic nucleus (STN) of patients undergoing stereotactic surgery in PD. We use the network of conductance based models of excitatory subthalamic and inhibitory pallidal cells (following [3]) to study intermittent activity in the model of BG circuits. We rely on the approach of detection of statistically significant episodes of phase-locking activity developed by us and colleagues [4] to characterize intermittent

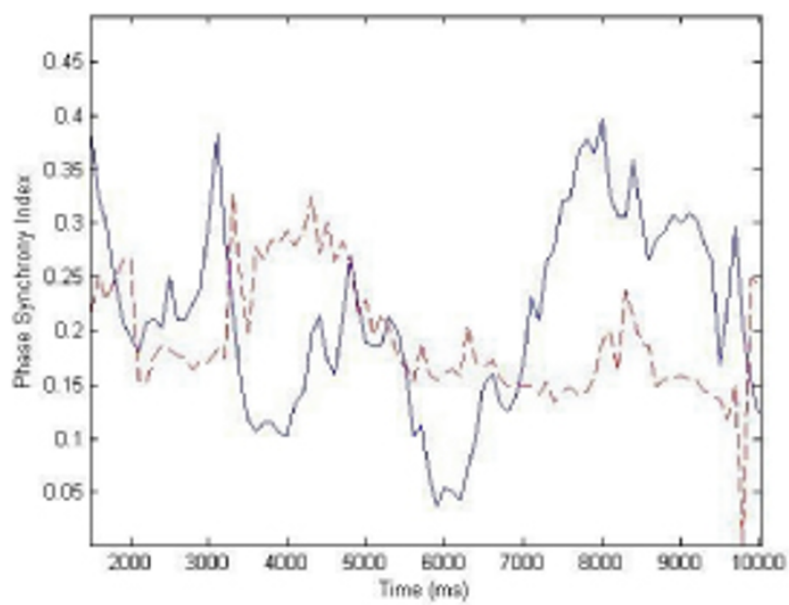

\section{Figure I}

The evolution of a phase synchrony index (solid line) computed over Is window in the real data (left) and model (right). The dashed line represents the $95 \%$ confidence level for the index (obtained with surrogate data). 
patterns of synchronous activity between spiking units and local field potentials (LFP) in the data and the model.

\section{Results}

The synchronous episodes are short-lived and intermittent. We explored the model to find the activity similar to the real one according to qualitative (similarity of first return maps) and quantitative criteria. An example of dynamics in the model and data is at the Figure 1. We explore the conditions under which intermittent synchronization arises.

\section{Discussion}

The properties and mechanisms of the intermittent activity as well as its functional significance are discussed.

\section{Acknowledgements}

Supported by Indiana University Purdue University Indianapolis RSFG grant.

\section{References}

I. Hutchison WD, Dostrovsky JO, Walters JR, Courtemanche R, Boraud T, Goldberg J, Brown P: Neuronal oscillations in the basal ganglia and movement disorders: evidence from whole animal and human recordings. J Neurosci 2004, 24:9240-9243.

2. Hammond C, Bergman H, Brown P: Pathological synchronization in Parkinson's disease: networks, models and treatments. Trends Neurosci 2007, 30:357-364.

3. Best J, Park C, Terman D, Wilson C: Transitions between irregular and rhythmic firing patterns in excitatory-inhibitory neuronal networks. J Comput Neurosci 2007, 23:217-235.

4. Hurtado JM, Rubchinsky LL, Sigvardt KA: Statistical method for detection of phase-locking episodes in neural oscillations. J Neurophysiol 2004, 91 : 1883-1898.
Publish with Biomed Central and every scientist can read your work free of charge

"BioMed Central will be the most significant development for disseminating the results of biomedical research in our lifetime. "

Sir Paul Nurse, Cancer Research UK

Your research papers will be:

- available free of charge to the entire biomedical community

- peer reviewed and published immediately upon acceptance

- cited in PubMed and archived on PubMed Central

- yours - you keep the copyright

Submit your manuscript here:

http://www.biomedcentral.com/info/publishing_adv.asp 